\title{
Case report: An adult-onset type II citrin deficiency patient in the emergency department
}

\author{
LUJIA TANG, LIANG CHEN, HAIRONG WANG, LIHUA DAI and SHUMING PAN \\ Emergency Department, Xin Hua Hospital Affiliated to Shanghai Jiao Tong University School of Medicine, \\ Shanghai 200092, P.R. China
}

Received February 21, 2015; Accepted April 12, 2016

DOI: $10.3892 /$ etm.2016.3298

\begin{abstract}
Mutations in the solute carrier family 25 (SLC25A13) gene may result in neonatal intrahepatic cholestasis caused by citrin deficiency and/or adult-onset type II citrullinemia. These conditions are inherited in an autosomal recessive manner. The current case report describes a 43-year-old man who presented with sudden delirium and upper limb weakness. Upon admission, the patient was fully conscious and alert but later lost consciousness subsequent to a sudden convulsive seizure. Hyperammonemia was detected and analysis of the SLC25A13 gene identified an 851del4 mutation. Thus, the possibility of genetic disease should be considered as a potential cause of the symptoms of patients with altered states of consciousness, such as delirium and loss of consciousness, in cases where the cause of the disturbance is unknown.
\end{abstract}

\section{Introduction}

Adult-onset type II citrullinemia (CTLN2) is a disorder caused by mutations in the solute carrier family 25 (SLC25A13) gene. CTLN2 is an autosomal recessive disorder characterized by recurrent encephalopathy with hyperammonemia resulting from high plasma citrulline and ammonium levels, which are caused by a deficiency of argininosuccinate synthetase in the liver. The literature concerning incidence rates of the disease is limited. According to a study by Nagata et al (1) in 1993, the incidence rate of CTLN2 was $1 / 100,000$ to $1 / 230,000$; however, the carrier and incidence rates differ across Japanese populations. CTLN2 is a genetic disease that does not have clear etiology, but usage of alcohol and certain drugs may represent risk factors. The clinical presentation of patients with CLTN2 is characterized by a hyperammonemia accompanied

Correspondence to: Professor Shuming Pan, Emergency Department, Xin Hua Hospital Affiliated to Shanghai Jiao Tong University School of Medicine, 1665 Kong Jiang Road, Shanghai 200092, P.R. China

E-mail: drshumingpan@126.com

Key words: adult-onset type II citrullinemia, CTLN2, citrin deficiency by recurrent episodes of neuropsychiatric manifestations, including aberrant behavior, nocturnal delirium, disorientation, consciousness disturbances, convulsive seizures and coma (2). Typical current therapies include liver transplantation, avoidance of protein-rich foods and treatment with arginine. The present study reports the case of a patient with type II citrullinemia who was misdiagnosed in the emergency department, and was finally administered arginine upon diagnosis of CTLN2.

\section{Case report}

A 43-year-old man was admitted to the emergency department of Xin Hua Hospital Affiliated to Shanghai Jiao Tong University School of Medicine (Shanghai, China) as a result of sudden delirium and upper limb weakness. The patient was unable to write due to upper limb weakness occurring $2 \mathrm{~h}$ prior to his admittance to the hospital, and experienced memory loss subsequent to informing his wife of the incident. The patient's wife stated that he became confused and was unable to answer questions appropriately. The patient had a medical history of left kidney angiomyolipoma at 3-years-old, and repeatedly complained of chest pain following physical activity over the previous 3-5 years, but had not undergone treatment for this. The patient had no history of hypertension or diabetes, is a non-drinker and had quit smoking several years previously.

Upon admission, the patient appeared to be fully conscious. He was aware of the time, place and his own age. He informed the doctors that the only thing he was able to remember was the paramedics taking him into the ambulance. The patient's blood pressure was 146/89 mmHg. Physical and neurological examinations revealed no abnormalities at that time. Computed tomography (CT) of the head revealed a mild cerebral edema and a region of minor hyperintensities in the right basal ganglia (Figs. 1 and 2). Laboratory data was predominantly normal. The patient was admitted to a ward of the neurosurgery department $6 \mathrm{~h}$ after arrival in the emergency department.

The patient began to experience a low-grade fever on day 2, the highest temperature of which, determined by axillary measurement, reaching $37.2^{\circ} \mathrm{C}$. The patient lost consciousness following a sudden convulsive seizure on the 3rd day after admission. A repeat CT head scan was performed, and magnetic resonance imaging and magnetic resonance 
angiography (MRA) scans revealed a mild cerebral edema, bilateral centrum semiovale and subcortex discrete lacunar infarction. MRA results were normal (20\% mannitol, $125 \mathrm{ml}$ IV q12h). The patient was administered mannitol intravenously to alleviate the brain edema. The patient also underwent a lumbar puncture on day 3 . The results of cerebrospinal fluid (CSF) analysis were abnormal (Table I). A pink color and increase of red blood cells in the CSF was considered to be indicative of haemorrhage during the procedure. The neurologist believed than an infection of the central nervous system should not be eliminated as a possible cause. Therefore, the patient received anti-epileptic (sodium valproate), antibiotic and antiviral treatment (sulperazon, amikacin and acyclovir). The patient's axillary temperature rose to $37.9^{\circ} \mathrm{C}$ on the morning of the 4th day, but the fever remitted in the evening and the patient regained consciousness at approximately the same time. His temperature remained normal for the following 3 days, and the patient underwent further lumbar puncture and CSF analysis, in addition to a T-SPOT TB test. The T-SPOT TB test was negative and the results of CSF analysis (Table II) were similar to those of the initial analysis displayed in Table I. The neurologist administered the patient ceftriaxone sodium, amikacin and acyclovir.

On day 8 , the patient began to convulse and became intermittently confused without displaying any indicators of a fever, and lost consciousness after a sudden convulsive seizure on the 9th day. An electroencephalogram performed on the 9th day revealed that activity in the two frontal lobes and central zone included $1-3 \mathrm{Ci} / \mathrm{sec}(\mathrm{Hz})$ high electric potential $\delta$ wave and triphase waves, which were produced by increased activity in the frontal lobes; metencephalon activity consisted of 3-5 c/s medium electric potential $\delta$ and $\theta$ waves, and brain waves were more rapid following the application of a stimulus. The neurologist believed that the possibility of Creutzfeldt-Jakob disease should not be eliminated, however, the family refused an additional lumbar puncture intended to be used to identify the relevant proteins. The plasma ammonium was observed to be higher than the normal range on the 9 th day $(170 \mu \mathrm{mol} / \mathrm{l}$; reference range, 9-33 $\mu \mathrm{mol} / \mathrm{l}$ ).

Geneticist and gastroenterologist consultations were requested immediately. The geneticist suggested that a citrin deficiency was possible. Tandem ammonia mass spectrometry (MS/MS) analysis of the blood and gas chromatography/mass spectrometry (GC/MS) profiling of urine samples from the patient were performed. The results of the MS/MS analysis of the patient's blood revealed high citrulline and free carnitine concentrations and a low acylcarnitine concentration at certain points (Table III). The results of the GC/MS analysis of a urine sample indicated that the concentrations of tyrosine metabolites such as 4-hydroxy phenyl lactic acid-2 and 4-hydroxy phenylpyruvic acid-OX-2 were high compared with the reference range (Table IV). Genomic DNA was extracted from the peripheral blood of the patient and his parents after obtaining written informed consent. The sequences of the SLC25A13 gene were determined. A single mutation in 851del4 inherited from the patient's parents was identified (Fig. 3).

Subsequent to the diagnosis of CTLN2, the patient was treated with arginine and a carbohydrate-restricted high-fat high-protein diet. The patient also received an invasive mechanical treatment for pulmonary infection and respiratory
Table I. Results of the cerebrospinal fluid analysis on day 3.

\begin{tabular}{lcc}
\hline Parameter & Result & Reference range \\
\hline Opening pressure & $17 \mathrm{cmH}_{2} \mathrm{O}$ & $5-18 \mathrm{cmH}_{2} \mathrm{O}$ \\
Glucose & $3.7 \mathrm{mmol} / 1$ & $3.3-4.4 \mathrm{mmol} / 1$ \\
Protein & $380.1 \mathrm{mg} / 1$ & $150-450 \mathrm{mg} / 1$ \\
Chloridum & $121 \mathrm{mmol} / 1$ & $120-132 \mathrm{mmol} / 1$ \\
Leukocytes & $14 \times 10^{6} / 1$ & $0-8 \times 10^{6} / 1$ \\
Erythrocytes & $20,000 \times 10^{6} / 1$ & $<10 \times 10^{6} / 1$ \\
Gross appearance & Pink & Clear and colorless \\
Culture & Sterile & Sterile \\
Gram stain & Negative & Negative \\
\hline
\end{tabular}

Table II. Result of the repeated cerebrospinal fluid analysis.

\begin{tabular}{lcc}
\hline Parameter & Result & Reference range \\
\hline Opening pressure & $16 \mathrm{cmH}_{2} \mathrm{O}$ & $5-18 \mathrm{cmH}_{2} \mathrm{O}$ \\
Glucose & $3.0 \mathrm{mmol} / 1$ & $3.3-4.4 \mathrm{mmol} / 1$ \\
Protein & $358.2 \mathrm{mg} / \mathrm{l}$ & $150-450 \mathrm{mg} / 1$ \\
Chloridum & $127 \mathrm{mmol} / 1$ & $120-132 \mathrm{mmol} / 1$ \\
Leukocytes & $21 \times 10^{6} / 1$ & $0-8 \times 10^{6} / 1$ \\
Erythrocytes & $220 \times 10^{6} / 1$ & $<10 \times 10^{6} / 1$ \\
Gross appearance & Pink & Clear and colorless \\
Culture & sterile & Sterile \\
Gram stain & \pm & Negative \\
\hline
\end{tabular}

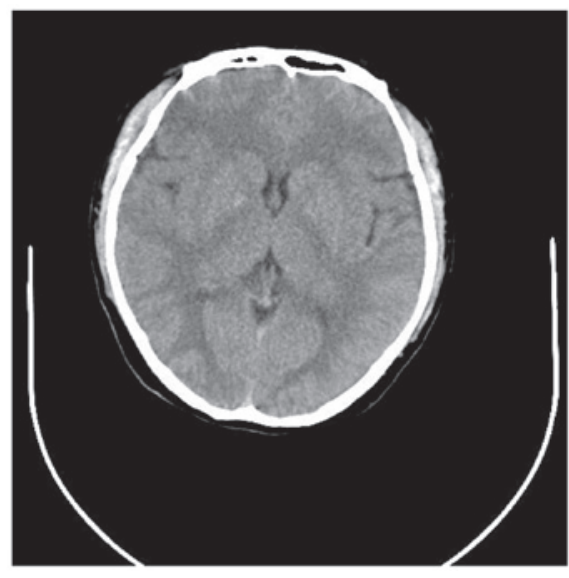

Figure 1. Computed tomography scan of the head revealed a small region of hyperintensity at the right basal ganglia.

failure, and was then discharged. The patient returned to the emergency department of Xin Hua Hospital Affiliated to Shanghai Jiao Tong University School of Medicine 7 months after discharge as a result of sudden alterations to consciousness, with no obvious extrinsic causes. The plasma ammonium level was $40 \mu \mathrm{mol} / 1$, which was close to normal. The emergency physician initiated treatment with arginine after excluding other possible diseases, which may have lead to an alteration to the level of consciousness. The patient recovered $2 \mathrm{~h}$ 
Table III. MS/MS of blood.

\begin{tabular}{|c|c|c|c|c|}
\hline Assessed index & Result & Unit & Level & $\begin{array}{c}\text { Reference } \\
\text { range }\end{array}$ \\
\hline Ala-1 & 59.38 & $\mu \mathrm{M}$ & Low & $60-300$ \\
\hline Asp-1 & 32.16 & $\mu \mathrm{M}$ & & $10-80$ \\
\hline Glu-1 & 66.04 & $\mu \mathrm{M}$ & & $45-200$ \\
\hline Met-1 & 12.61 & $\mu \mathrm{M}$ & & $8-35$ \\
\hline Phe-1 & 32.39 & $\mu \mathrm{M}$ & & $20-120$ \\
\hline Tyr-1 & 34.81 & $\mu \mathrm{M}$ & & $20-100$ \\
\hline Leu-1 & 56.52 & $\mu \mathrm{M}$ & & $50-250$ \\
\hline Trp-1 & 11.79 & $\mu \mathrm{M}$ & & $10-75$ \\
\hline Val-1 & 85.9 & $\mu \mathrm{M}$ & & $80-300$ \\
\hline Arg-1 & 8.9 & $\mu \mathrm{M}$ & & $1.5-25$ \\
\hline Cit-1 & 59.3 & $\mu \mathrm{M}$ & High & $7-35$ \\
\hline Gly-1 & 134.65 & $\mu \mathrm{M}$ & & $90-350$ \\
\hline Orn-1 & 28.64 & $\mu \mathrm{M}$ & & $15-80$ \\
\hline Gln-1 & 8.33 & $\mu \mathrm{M}$ & & $6-30$ \\
\hline His-1 & 59.44 & $\mu \mathrm{M}$ & & $10-300$ \\
\hline Ser-1 & 28.99 & $\mu \mathrm{M}$ & & $20-100$ \\
\hline Thr-1 & 36.48 & $\mu \mathrm{M}$ & & $15-100$ \\
\hline Arg/Orn-1 & 0.31 & & & $0-0.7$ \\
\hline Cit/Arg-1 & 6.66 & & & $0.6-10$ \\
\hline Orn/Cit-1 & 0.48 & & Low & $0.8-4$ \\
\hline Met/Phe-1 & 0.39 & & & $0.2-0.6$ \\
\hline Leu/Phe-1 & 1.73 & & & $1.5-4$ \\
\hline Phe/Tyr-1 & 0.93 & & & $0.5-2$ \\
\hline Gly/Phe-1 & 4.16 & & & $1.5-10$ \\
\hline $\mathrm{C} 0-1$ & 6.6 & $\mu \mathrm{M}$ & Low & $10-60$ \\
\hline C2-1 & 2.98 & $\mu \mathrm{M}$ & Low & $6-30$ \\
\hline C3-1 & 0.52 & $\mu \mathrm{M}$ & & $0.5-4$ \\
\hline C3DC-1 & 0.023 & $\mu \mathrm{M}$ & & $0-0.4$ \\
\hline C4-1 & 0.098 & $\mu \mathrm{M}$ & & $0.06-0.5$ \\
\hline C4-OH-1 & 0.038 & $\mu \mathrm{M}$ & & $0-0.35$ \\
\hline C4DC-1 & 0.28 & $\mu \mathrm{M}$ & & $0.2-1.2$ \\
\hline C5-1 & 0.04 & $\mu \mathrm{M}$ & & $0.04-0.3$ \\
\hline C5:1-1 & 0.016 & $\mu \mathrm{M}$ & & $0-0.1$ \\
\hline C5-OH-1 & 0.16 & $\mu \mathrm{M}$ & & $0.06-0.6$ \\
\hline C5DC-1 & 0.033 & $\mu \mathrm{M}$ & & $0-0.2$ \\
\hline C6-1 & 0.035 & $\mu \mathrm{M}$ & & $0.01-0.15$ \\
\hline C6:1-1 & 0.015 & $\mu \mathrm{M}$ & & $0-0.1$ \\
\hline C6DC-1 & 0.019 & $\mu \mathrm{M}$ & & $0-0.06$ \\
\hline C8-1 & 0.035 & $\mu \mathrm{M}$ & & $0.01-0.3$ \\
\hline C8:1-1 & 0.016 & $\mu \mathrm{M}$ & Low & $0.03-0.5$ \\
\hline C8DC-1 & 0.018 & $\mu \mathrm{M}$ & & $0-0.04$ \\
\hline C10-1 & 0.032 & $\mu \mathrm{M}$ & & $0.02-0.5$ \\
\hline C10:1-1 & 0.042 & $\mu \mathrm{M}$ & & $0.03-0.45$ \\
\hline C12-1 & 0.025 & $\mu \mathrm{M}$ & & $0.02-0.2$ \\
\hline C12:1-1 & 0.03 & $\mu \mathrm{M}$ & & $0-0.02$ \\
\hline C14-1 & 0.035 & $\mu \mathrm{M}$ & & $0.02-0.25$ \\
\hline C14:1-1 & 0.053 & $\mu \mathrm{M}$ & & $0.01-0.3$ \\
\hline C14-OH-1 & 0.01 & $\mu \mathrm{M}$ & & $0-0.06$ \\
\hline C16-1 & 0.23 & $\mu \mathrm{M}$ & Low & $0.3-2$ \\
\hline C16:1-1 & 0.016 & $\mu \mathrm{M}$ & & $0-0.2$ \\
\hline C16-OH-1 & 0.09 & $\mu \mathrm{M}$ & & $0-0.05$ \\
\hline
\end{tabular}

Table III continued.

\begin{tabular}{|c|c|c|c|c|}
\hline C18-1 & 0.21 & $\mu \mathrm{M}$ & & $0.2-1.2$ \\
\hline C18:1-1 & 0.3 & $\mu \mathrm{M}$ & Low & $0.3-1.8$ \\
\hline C18-OH-1 & 0.006 & $\mu \mathrm{M}$ & & $0-0.03$ \\
\hline
\end{tabular}

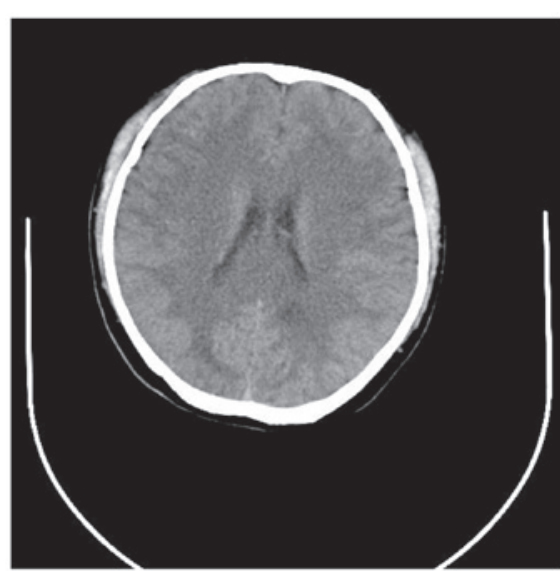

Figure 2. Computed tomography scan of the head indicated mild cerebral edema.

later and was discharged from the hospital the following day. However, the patient returned to the emergency department again several days later with hyperammonemia $(88 \mu \mathrm{mol} / \mathrm{l})$. A physician administered arginine for several days. The patient is currently still undergoing follow-up examination.

\section{Discussion}

The term CITRIN was coined in 1999 to represent the protein product encoded by the SLC25A13 gene, which was localized to chromosome 7q21.3 and determined to be the causative gene of adult-onset CTLN2 $(3,4)$. SLC25A13 mutations result in citrin deficiency (CD). CTLN2 was the initial CD phenotype to be described, occurring in adolescents or adults, and the prognosis is typically poor $(4,5)$. Manifestations include recurrent hyperammonemia with neuropsychiatric symptoms including nocturnal delirium, aggression, delusions, disorientation, restlessness, loss of memory, convulsive seizures and coma; death can result from brain edema. Symptoms are often induced as a result of alcohol and sugar intake, medication, infection and/or surgery (5).

In the human body, the urea cycle is the major pathway used for the removal of waste nitrogen, and aberrances of this pathway exist, as in CTLN2 (6). Citrullinemia is caused by a deficiency of the urea cycle enzyme argininosuccinate synthetase, which catalyzes the ligation reaction of citrulline (Cit) and aspartate to form argininosuccinate. The loss of argininosuccinate synthetase activity results in an accumulation of plasma Cit and ammonia in patients (7).

The current case was the first treatment of a CTLN2 patient in the emergency department of Xin Hua Hospital, although this diagnosis was not apparent initially due to atypical symptoms, including sudden delirium and upper limb weakness, which usually indicate shock. CTLN2 is characterized by recurrent 
Table IV. Gas chromatography/mass spectrometry analysis of the patient's urine.

\begin{tabular}{|c|c|c|c|}
\hline Assessed index & Result & Abnormal & $\begin{array}{c}\text { Reference } \\
\text { range }\end{array}$ \\
\hline PA-OX-2 & 1.5 & & $0-24.1$ \\
\hline VPA-1 & 4.86 & Yes & 0 \\
\hline Carbamide-2 & 8.51 & & $104.6-763$ \\
\hline 2-Keto-3-Methylpentanoic acid-2 & 0.17 & & 0 \\
\hline Orthophosphoric acid-3 & 31.59 & & $0-43$ \\
\hline Succinic acid-2 & 3.5 & & $6.5-65.8$ \\
\hline Uracil-2 & 2.2 & & $0-7$ \\
\hline Malic acid-3 & 0.22 & & $0-0.7$ \\
\hline Hexanedioic acid-2 & 3.98 & & $0.5-5$ \\
\hline 2-propyl-hydroxy glutaric acid-2 & 12.99 & Yes & 0 \\
\hline 7-hydroxyoctanoate-2 & 0.14 & Yes & 0 \\
\hline 2-hydroxyglutarate-3 & 0.86 & & $0.6-5.9$ \\
\hline Phenyllactic acid-2 & 1.54 & & $0-4.9$ \\
\hline Pimelic acid-2 & 0.73 & & $0-9.3$ \\
\hline 3-hydroxyphenylacetic acid-2 & 0.25 & & $0-0.9$ \\
\hline 4-hydroxyphenylacetic acid & 25.14 & & $8.6-73.2$ \\
\hline 2-ketoglutarate-OX-2 & 0.35 & & $0.3-21.3$ \\
\hline $\mathrm{N}$-phophonoacetyl aspartic acid-2 & 0.31 & & $0-3.7$ \\
\hline 2-hydroxyhexanedioic acid-3 & 3.92 & Yes & $0-2$ \\
\hline Octandioic acid-2 & 0.69 & & $0.4-4.7$ \\
\hline Orotic acid-3 & 0.29 & & $0-1.5$ \\
\hline Vanillic acid-2 & 0.18 & & 0 \\
\hline Azelaic acid-2 & 1.01 & & $9-10.7$ \\
\hline Citric acid-4 & 173.21 & & $31.4-572.3$ \\
\hline Alkapton-3 & 0.08 & & $0-1.4$ \\
\hline Hippuric acid-1 & 3.75 & & $6.2-284.1$ \\
\hline VMA-3 & 13.41 & & $11.7-84.6$ \\
\hline Sebacic acid-2 & 0.72 & & $0.4-7$ \\
\hline Decadienoic acid-3 & 1.08 & & $0-2.3$ \\
\hline 4-hydroxy phenyl lactic acid-2 & 59.1 & Yes & $0-7$ \\
\hline 4-hydroxy phenylpyruvic acid-OX-2 & 3.96 & Yes & $0-0.9$ \\
\hline Hexadecanoic acid-1 & 10.38 & & $0-13.8$ \\
\hline 2-hydroxyhippuric acid-3 & 3.96 & & 0 \\
\hline
\end{tabular}

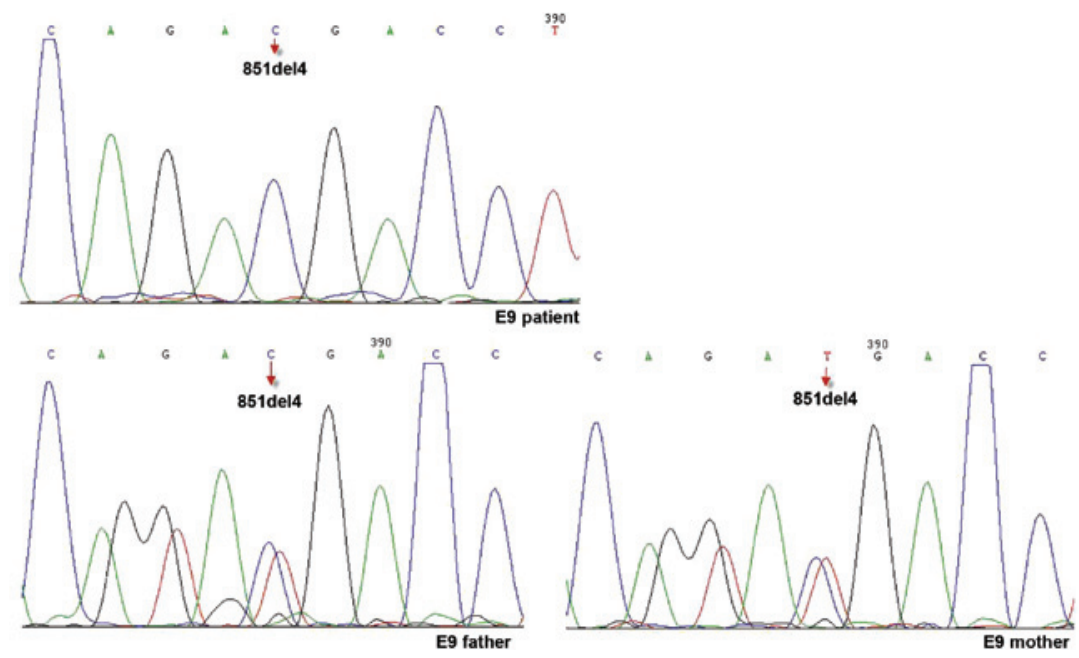

Figure 3. A single mutation of 851 del 4 was identified from the peripheral blood of the patient, which had been inherited from his parents. 
encephalopathy with hyperammonemia and may be misdiagnosed as other neurological or psychiatric diseases $(8,9)$. The present study did not assess the plasma ammonia levels until the 9th day, and led to a positive diagnosis the following day. The oversight in failing to assess plasma ammonia levels was a hindrance to a rapid diagnosis. Cases of hyperammonemia that present without a history of hepatic disease are usually the primary indicator of abnormal laboratory data. CTLN2 should be considered in the event of neuropsychiatric manifestations, even in cases presenting without hyperammonemia. For instance, Takahashi et al (2), reported an adult-onset type II citrullinemia case without hyperammonemia. From the current case, it was determined that the patient may display neuropsychiatric symptoms even with a lower plasma ammonium level than those usually associated with CTLN2.

The most successful therapy to date for the treatment of CTLN2 has been liver transplantation, which prevents episodic hyperammonemic crises, corrects metabolic disturbances and eliminates necessity for protein-rich foods $(4,8,10-12)$. Administration of arginine was reported to be effective in decreasing plasma ammonium concentration. Reducing calorie/ carbohydrate intake and increasing protein intake ameliorates hypertriglyceridemia (13). The present patient was treated with arginine and a carbohydrate-restricted, high-fat and high-protein diet. The patient's family would not consider liver transplantation due to the high cost associated with this. It was appropriate for the physician to select mannitol in preference to glycerol as glycerol contains $5 \%$ fructose, which may affect cytosolic nicotinamide adenine dinucleotide (NADH) production and aggravate the symptoms (9). It is recommended that any high-sugar solutions such as fructose and glucose should be excluded from the diet as they may elevate the cytosolic NADH/NAD+ ratio in the liver and exacerbate the encephalopathy $(9,14,15)$.

In conclusion, emergency physicians should consider CTLN2 as a differential diagnosis in patients with sudden neuropsychiatric symptoms, and plasma ammonium levels should not be ignored.

\section{References}

1. Nagata N, Matsuda I, and Oyanagi K: Estimated frequency of urea cycle enzymopathies in Japan. Am J Med Genet 39: 228-229, 1991.

2. Takahashi Y, Koyama S, Tanaka H, Arawaka S, Wada M, Kawanami T, Haga H, Watanabe H, Toyota K, Numakura C, et al: An elderly Japanese patient with adult-onset type II citrullinemia with a novel D493G mutation in the SLC25A13 gene. Intern Med 51: 2131-2134, 2012.
3. Kobayashi K, Sinasac DS, Iijima M, Boright AP, Begum L, Lee JR, Yasuda T, Ikeda S, Hirano R, Terazono H, et al: The gene mutated in adult-onset type II citrullinaemia encodes a putative mitochondrial carrier protein. Nat Genet 22: 159-163, 1999.

4. Song YZ, Zhang ZH, Lin WX, Zhao XJ, Deng M, Ma YL, Guo L, Chen FP, Long XL, He XL, et al: SLC25A13 gene analysis in citrin deficiency: Sixteen novel mutations in East Asian patients, and the mutation distribution in a large pediatric cohort in China. PLoS One 8: e74544, 2013.

5. Kobayashi K, Saheki T and Song YZ: Citrin Deficiency. In: GeneReviews. Pagon RA, Bird TD, Dolan CR, Stephens K, Adam MP (eds). University of Washington, Seattle, WA, 2005.

6. Honda S, Yamamoto K, Sekizuka M, Oshima Y, Nagai K, Hashimoto G, Kaneko H, Tomomasa T, Konno Y and Horiuchi R: Successful treatment of severe hyperammonemia using sodium phenylacetate powder prepared in hospital pharmacy. Biol Pharm Bull 25: 1244-1246, 2002.

7. Sinasac DS, Moriyama M, Jalil MA, Begum L, Li MX, Iijima M, Horiuchi M, Robinson BH, Kobayashi K, Saheki T and Tsui LC: Slc25a13-knockout mice harbor metabolic deficits but fail to display hallmarks of adult-onset type II citrullinemia. Mol Cell Biol 24: 527-536, 2004.

8. Ikeda S, Yazaki M, Takei Y, Ikegami T, Hashikura Y, Kawasaki S, Iwai M, Kobayashi K and Saheki T: Type II (adult onset) citrullinaemia: Clinical pictures and the therapeutic effect of liver transplantation. J Neurol Neurosurg Psychiatry 71: 663-670, 2001.

9. Takahashi H, Kagawa T, Kobayashi K, Hirabayashi H, Yui M, Begum L, Mine T, Takagi S, Saheki T and Shinohara Y: A case of adult-onset type II citrullinemia-deterioration of clinical course after infusion of hyperosmotic and high sugar solutions. Med Sci Monit 12: CS13-CS15, 2006.

10. Yazaki M, Hashikura Y, Takei Y, Ikegami T, Miyagawa S, Yamamoto K, Tokuda T, Kobayashi K, Saheki T and Ikeda S: Feasibility of auxiliary partial orthotopic liver transplantation from living donors for patients with adult-onset type II citrullinemia. Liver Transpl 10: 550-554, 2004.

11. Hirai I, Kimura W, Suto K, Fzjimoto H, Watanabe T, Fuse A, Kobayashi K, Iijima M, Saheki T, Nakatsuka T, et al: Living donor liver transplantation for type II citrullinemia from a heterozygous donor. Hepatogastroenterology 55: 2211-2216, 2008.

12. Kobayashi $\mathrm{K}$ and Saheki T: Molecular basis of citrin deficiency. Seikagaku 76: 1543-1559, 2004 (In Japanese).

13. Imamura Y, Kobayashi K, Shibatou T, Aburada S, Tahara K, Kubozono $\mathrm{O}$ and Saheki T: Effectiveness of carbohydrate-restricted diet and arginine granules therapy for adult-onset type II citrullinemia: A case report of siblings showing homozygous SLC25A13 mutation with and without the disease. Hepatol Res 26: 68-72, 2003.

14. Saheki T, Kobayashi K, Iijima M, Horiuchi M, Begum L, Jalil MA, Li MX, Lu YB, Ushikai M, Tabata A, et al: Adult-onset type II citrullinemia and idiopathic neonatal hepatitis caused by citrin deficiency: Involvement of the aspartate glutamate carrier for urea synthesis and maintenance of the urea cycle. Mol Genet Metab 81 (Suppl 1): S20-S26, 2004.

15. Yazaki M, Takei Y, Kobayashi K, Saheki T and Ikeda S: Risk of worsened encephalopathy after intravenous glycerol therapy in patients with adult-onset type II citrullinemia (CTLN2). Intern Med 44: 188-195, 2005. 